\title{
Hard carbon coated nano-Si/graphite composite as a high performance anode for Li-ion batteries
}

Sookyung Jeong, ${ }^{a}$ Xiaolin Li, ${ }^{a}$ Jianming Zheng, ${ }^{a}$ Pengfei Yan, ${ }^{b}$ Ruiguo Cao, ${ }^{a}$ Hee Joon Jung, ${ }^{a}$ Chongmin Wang, ${ }^{\mathrm{b}}$ Jun Liu, ${ }^{\mathrm{a}}$ and Ji-Guang Zhang ${ }^{\mathrm{a} *}$

a Pacific Northwest National Laboratory, 902 Battelle Blvd., Richland, Washington 99352

b Environmental Molecular Sciences Laboratory, Pacific Northwest National Laboratory, Richland, WA 99352

Correspondence should be addressed to: E-mail: Jiguang.zhang@pnnl.gov

\begin{abstract}
With the ever-increasing demands for higher energy densities in Li-ion batteries, alternative anodes with higher reversible capacity are required to replace the conventional graphite anode. Here, we demonstrate a cost-effective hydrothermal carbonization approach to prepare a hard carbon coated nano-Si/graphite (HC-nSi/G) composite as a high performance anode for Li-ion batteries. In this hierarchical structured composite, the hard carbon coating not only provides an efficient pathway for electron transfer, but also alleviates the volume variation of $\mathrm{Si}$ during charge/discharge processes. The $\mathrm{HC}-\mathrm{nSi} / \mathrm{G}$ composite electrode shows excellent performance, including a high specific capacity of $878.6 \mathrm{mAh} \mathrm{g}^{-1}$ based on the total weight of composite, good rate performance, and a decent cycling stability, which is promising for practical applications.
\end{abstract}

Keywords: Si/graphite composites; hard carbon coating; cycling performance; rate capability; lithium ion batteries 


\section{Graphical abstract}

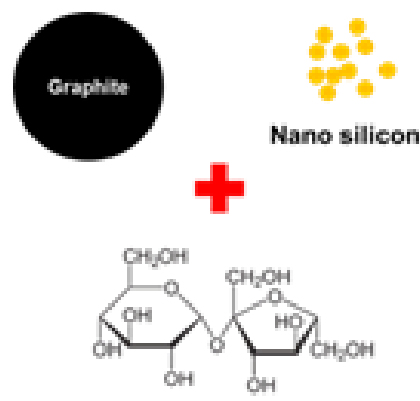

Sucrose

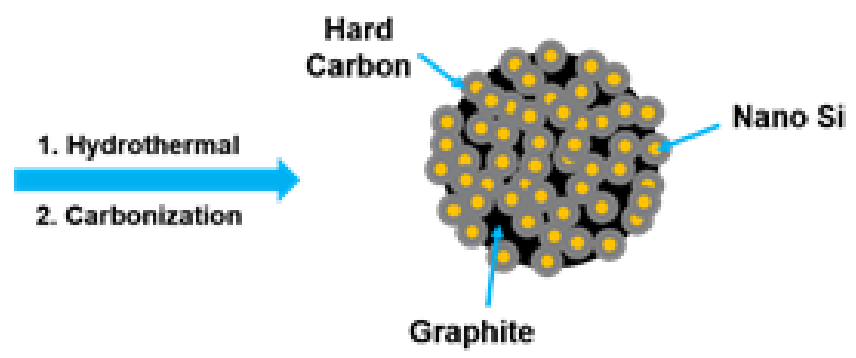




\section{Introduction}

Li-ion batteries (LIBs) have been widely used in electric vehicles (EVs) due to their high energy density, long-term cycle life, and environmental benignity. However, the limited specific capacity $\left(\sim 350 \mathrm{mAh} \mathrm{g}^{-1}\right)$ of graphite anode used in the state-of-the-art LIBs is one of the key barriers to the development of high energy density batteries. Batteries with graphite electrodes have an energy density of $<200 \mathrm{Wh} \mathrm{kg}^{-1}$. As a result, the driving range of EVs using these batteries is limited to $<200 \mathrm{~km}$ in a single charge. ${ }^{1}$ Li-ion batteries with high energy density of $300 \mathrm{Wh} \mathrm{kg}^{-1}$ are required to meet the need for long range EVs. ${ }^{1,2}$ Therefore, alternative high capacity anode are urgently needed for large-scale market penetration of EVs. In this aspect, silicon has been regarded as one of the most promising anode material with its high theoretical specific capacity $\left(\sim 4200 \mathrm{mAh} \mathrm{g}^{-1}\right)$ at room temperature. ${ }^{3}$ However, because of the large volume expansion (> 300\%) of Si during lithiation/delithiation processes, silicon particles will be easily pulverized, which would lead to fast capacity fading. ${ }^{4,5}$ To circumvent these problems, Si with various nanostructures have been designed. These nanostructures include nanowires, ${ }^{6}$ nanotubes, ${ }^{7}$ nanoparicles, ${ }^{8}$ yolk-shell, ${ }^{9}$ and core-shell structure, ${ }^{10}$ which minimize the intrinsic problem of silicon during lithiation/delithiation processes. Recently, a novel sandwich-structured Si/graphene composite has been developed which included ordered magnesiothermo-reduced Si nanoparticles and thermally reduced graphene oxide and demonstrated good stability. ${ }^{13}$ Although these nano-structured Si can provide high capacity and good cycling stability, they often suffer from the high production costs and are difficult to scale up. Therefore, a low cost, scalable process of making Si based anode materials is needed. Considering the typical capacity of $150 \sim 200 \mathrm{mAh} \mathrm{g}^{-1}$ for the state of the art cathode material, a practical anode capacity of $\sim 600 \mathrm{mAh} \mathrm{g}^{-1}$ with a long term stability is a reasonable compromise between the high capacity and high stability requirement for anodes. ${ }^{11,12,13}$.

Here, we propose a facile and scalable strategy for preparation of the interconnected structure consisting of a hard carbon coated nano-Si/graphite (HC-nSi/G) composite. In this hierarchical architecture, hard carbon plays an important role in buffering the volume expansion of silicon during lithiation and providing the effective pathway for electron transfer, as well as functioning as active material. 
Furthermore, it is expected that nano-Si adhesion on graphite is well maintained by the hard carbon coating, which has strong mechanical properties.

\section{Experimental}

\subsection{Material synthesis and characterization}

Sample preparation and Characterization: The synthesis of the interconnected HC-nSi/G was carried out with a hydrothermal process followed by a carbonization step, as shown in Figure 1a. In detail, the solution of nano-Si powders (size $\sim 50 \mathrm{~nm}$, Alfa-Aesar) was prepared in $1.5 \mathrm{M}$ of sucrose solution with a few drops of ethanol to uniformly disperse the powder. After the addition of graphite (size $\sim 10 \mu \mathrm{m}$, Superior graphite), the mixture was stirred for $1 \mathrm{~h}$ at $50^{\circ} \mathrm{C}$ and then placed in Teflon-lined stainless steel autoclave. The hydrothermal reaction was carried out at $190{ }^{\circ} \mathrm{C}$ for $6 \mathrm{~h}$. The product was further dried at $110^{\circ} \mathrm{C}$ overnight to remove the residual water, followed by being carbonized at $1000^{\circ} \mathrm{C}$ for $6 \mathrm{~h}$ in $\mathrm{Ar}$ atmosphere to produce hard carbon structure. The final product was composed of $45.8 \mathrm{wt} \%$ of graphite, $14.6 \mathrm{wt} \%$ of nano-Si and $39.6 \mathrm{wt} \%$ of hard carbon. For pre-lithiation step, the stabilized lithium metal powder (SLMP, FMC Inc.) was scattered on the dried electrode prior to cell assembly and compressed. As a reference sample, mechanically blend graphite/nano-Si/hard carbon (BGSH) was prepared by simply mixing the graphite, nano-Si, and hard carbon with same weight ratio of $\mathrm{HC}-\mathrm{nSi} / \mathrm{G}$ sample. Powder X-ray diffraction (XRD) of the synthesized samples was performed on a Rikagu MiniFlex II with $\mathrm{Cu} \mathrm{K} \alpha$ radiation operated at $30 \mathrm{kV}$ and $15 \mathrm{~mA}$. Data were collected in the $2 \theta$ range of $10-80^{\circ}$ at $0.5^{\circ} \min ^{-1}$. Scanning electron microscopy (SEM) studies were performed on a FEI Quanta FE-SEM at an accelerating voltage of $5 \mathrm{kV}$. Transmission electron microscopy was performed on a JEOL-2010.

\subsection{Electrochemical measurements:}

Electrochemical performance measurements were carried out with R2032 coin-type cells. The electrodes were prepared by casting the homogeneous slurry consisting of active materials, carbon black, and sodium carboxymethyl cellulose (CMC) in a weight ratio of 70:10:20 or 80:10:10. A typical loading of 
the active material is $1.5 \sim 2.0 \mathrm{mg} \mathrm{cm}^{-2}$. After drying, the electrodes were punched into disks with an area of $1.27 \mathrm{~cm}^{2}$, and then dried at $70^{\circ} \mathrm{C}$ under vacuum overnight. Electrochemical cells were assembled with the electrode as prepared in an Ar-filled glove box using metallic Li chips as negative electrode, Celgard 2500 as separator, and $1 \mathrm{M} \mathrm{LiPF}_{6}$ in ethylene carbonate (EC)/ diethyl carbonate (DEC) with 10 wt\% fluoroethylene carbonate (FEC) additive as electrolyte. Charge-discharge experiments were performed galvanostatically on an Arbin BT-2000 battery tester at room temperature $\left(\sim 25^{\circ} \mathrm{C}\right)$. The voltage range for cycling stability and rate performance tests is between 0.005 and $1.5 \mathrm{~V}$ vs. $\mathrm{Li} / \mathrm{Li}^{+}$. A $1 \mathrm{C}$ rate corresponds to a current density of $600 \mathrm{~mA} \mathrm{~g}^{-1}$ in the present work. Cyclic voltammetry (CV) was tested using a $\mathrm{CH}$ Instruments at a scan rate of $0.1 \mathrm{mV} \mathrm{s}^{-1}$ in a voltage range of $0.005 \sim 1.5 \mathrm{~V}$. Electrochemical impedance spectroscopy was measured using the CHI660d workstation (CH Instruments, US) with a perturbation amplitude of $\pm 5 \mathrm{mV}$ at a frequency range between $10^{5} \mathrm{~Hz}$ and $10 \mathrm{mHz}$.

\section{Results and discussion}

Figure 1a describes schematically the detailed synthesis process for the $\mathrm{HC}-\mathrm{nSi} / \mathrm{G}$ composites. In order to coat the interconnected hard carbon/nano-Si on a graphite surface, a mixture solution of graphite (size $10 \mu \mathrm{m}$ ), nano-Si (size $\sim 50 \mathrm{~nm}$ ) and $1.5 \mathrm{M}$ of sucrose in water was subjected to a hydrothermal process, followed by a carbonization step to produce hard carbon structure from sucrose. The morphology of the prepared HC-nSi/G composite was examined using SEM, and the images are presented in Figure $1 \mathrm{~b}$ and 1c. At low magnification, $\mathrm{HC}-\mathrm{nSi} / \mathrm{G}$ exhibits agglomerated secondary particles with particle size of $\sim 10$ $\mu \mathrm{m}$ (Figure 1b). Higher magnification SEM images reveal that the surface of these large particles consist of interconnected nano-Si/hard carbon (Figure 1c). Elemental mapping analysis was carried out to better understand distribution of hard carbon and nano-Si at the surface of $\mathrm{HC}-\mathrm{nSi} / \mathrm{G}$ composite. The individual elemental mapping result is shown in Figure S1. The overlaid C/Si elemental maps as presented in Figure 1d reveals that nano-Si particles are well wrapped with hard carbon and the thickness of nano-Si particles/hard carbon the layer on graphite surface is $\sim 1 \mu \mathrm{m}$. The hard carbon coated nano-Si has good

adhesion to the graphite surface because of the hydrophobicity of carbon and graphite. ${ }^{14}$ The carbon 
coating layer on nano-Si particles is believed not only to be beneficial for an efficient electron transport but also to serve as a buffering zone to accommodate the volume change of nano-Si during lithiation/delithiation processes. ${ }^{15}$ The crystalline structure of $\mathrm{HC}-\mathrm{nSi} / \mathrm{G}$ as characterized by XRD (Figure 1e) shows XRD peaks that can be indexed to graphite (hexagonal phase, JCPDS\# 98-007-6767) and silicon (cubic phase, JCPDS\# 00-027-1402) without any SiC by-product detected.

(a)
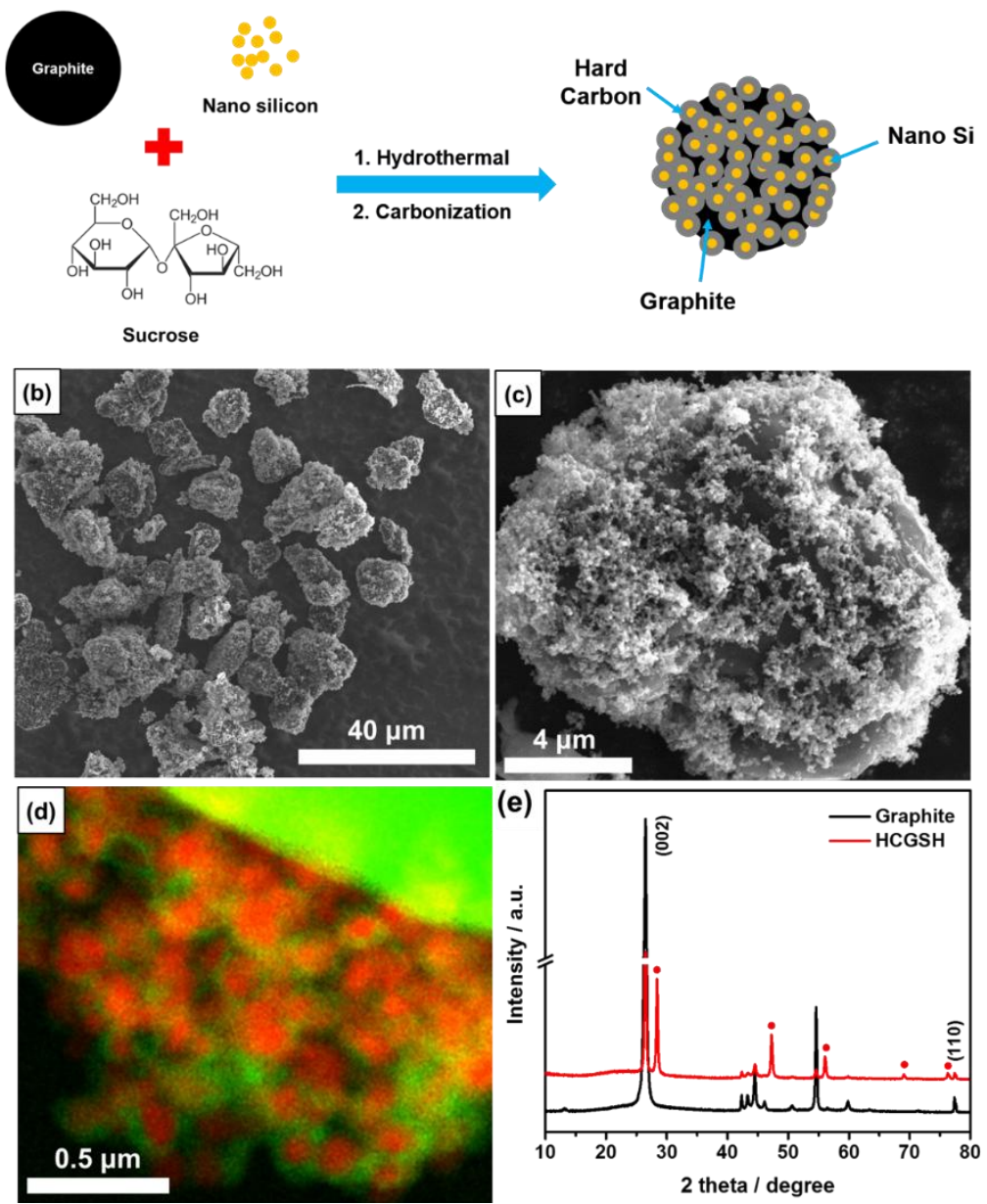

Figure 1. (a) Schematic illustration of the synthesis of the interconnected HC-nSi/G. (b and c) Low and high magnification SEM images showing the hierarchical structure of the HC-nSi/G composite. (d) Overlaid $\mathrm{C} / \mathrm{Si}$ energy-dispersive $\mathrm{X}$-ray spectroscopy elemental maps (green: carbon, red: silicon). (e) XRD patterns (red circle: silicon) of $\mathrm{HC}-\mathrm{nSi} / \mathrm{G}$ composite (graphite: JCPDS \#98-007-6767, silicon: JCPDS\# 00-027-1402). 
$\mathrm{CV}$ was first carried out to understand the electrochemical properties of $\mathrm{HC}-\mathrm{nSi} / \mathrm{G}$ composite and the results are shown in Figure 2a, in which the CV curves of mechanically blended graphite/nano-Si/hard carbon (BGSH) mixture is also shown for comparison. In the $\mathrm{CV}$ scan of $\mathrm{HC}-\mathrm{nSi} / \mathrm{G}$ after formation cycles, two cathodic peaks $(\sim 0.05$ and $\sim 0.15 \mathrm{~V})$ are observed in the negative scan while five anodic peaks $(\sim 0.13, \sim 0.215, \sim 0.28, \sim 0.34$ and $\sim 0.53 \mathrm{~V})$ are observed in the positive scan. The cathodic peaks at $\sim 0.15$ and $\sim 0.05 \mathrm{~V}$ can be attributed to the continuous lithiation of nano $\mathrm{Si}$ and graphite (stage III+IIL), respectively. ${ }^{16-18}$ The anodic peaks at $\sim 0.13$ and $\sim 0.22$ are ascribed to the delithiation of graphite, and the peaks at $\sim 0.28 \mathrm{~V}, \sim 0.34$ and $\sim 0.53 \mathrm{~V}$ are characteristic of the delithiation of amorphous $\mathrm{Si}$ (the crystalline structure of Si becomes amorphous after lithiation), respectively. On the other hand, in the CV scan of $\mathrm{BGSH}$, the cathodic/anodic peaks are located at similar potentials as compared to $\mathrm{HC}-\mathrm{nSi} / \mathrm{G}$, but the peak intensity is considerably weaker than those of $\mathrm{HC}-\mathrm{nSi} / \mathrm{G}$. This could be ascribed to the poor contact between nano $\mathrm{Si}$ and the graphite leading to inefficient electron transport for the mechanically blended samples. In the subsequent CV scans of $\mathrm{HC}-\mathrm{nSi} / \mathrm{G}$ (Figure S2), there is no obvious changes in the peak positions and the peak intensity, indicating a good reversibility of the HC-nSi/G composite prepared in this work.
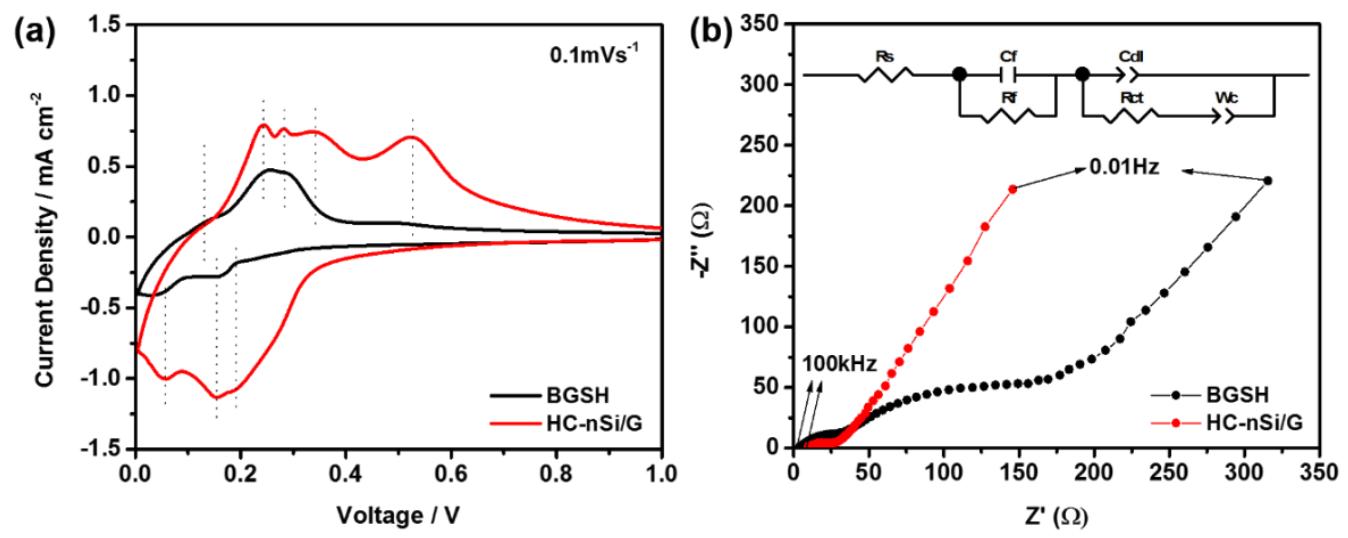

Figure 2. (a) Cyclic voltammograms vs. $\mathrm{Li} / \mathrm{Li}^{+}$at a scan rate of $0.1 \mathrm{mV} \mathrm{s}^{-1}$. (b) Nyquist plots of BGSH and the $\mathrm{HC}-\mathrm{nSi} / \mathrm{G}$ composite electrode in the range of 0.01 to $100 \mathrm{kHz}$ with $5 \mathrm{mV}$ amplitude (inset: 
equivalent Randle circuit). Both measurements were implemented after formation cycles at $0.05 \mathrm{C}(1 \mathrm{C}=$ $600 \mathrm{~mA} \mathrm{~g}^{-1}$ ) in the voltage range of $0.005 \sim 1.5 \mathrm{~V}$.

To further investigate the effects of the hard carbon coating, typical Nyquist plots of the composites materials were obtained after formation cycles, exhibiting two semi-circles in the high-to-medium frequency region and one slope in the low frequency region (Figure 2b). The first semi-circle in the high-to-medium frequency region corresponds to the impedance of Li-ion migration through solid electrolyte interphase (SEI) film, while the second semi-circle in the medium frequency region is ascribed to the impedance of charge-transfer related to the electrode surface. The linear slope at the low frequency range corresponds to the lithium ion diffusion in the bulk electrode. The equivalent Randle circuit (Figure $2 b$ inset) is proposed for fitting the impedance data, consisting of a series of resistors $\left(\mathrm{R}_{\mathrm{s}}\right.$ : ohmic resistance, $\mathrm{R}_{\mathrm{f}}$ : the resistance of the SEI film and contact point, $\mathrm{R}_{\mathrm{ct}}$ : charge-transfer resistance), constant phase elements $\left(\mathrm{C}_{\mathrm{dl}}\right)$, capacitance corresponding to SEI film $\left(\mathrm{C}_{\mathrm{f}}\right)$, and Warburg impedance $\left(\mathrm{W}_{\mathrm{c}}\right)$. As summarized in Table $\mathrm{S} 1$, The $\mathrm{R}_{\mathrm{f}}$ value $(8.59 \Omega)$ of BGSH is higher than that $(3.59 \Omega)$ of $\mathrm{HC}-\mathrm{nSi} / \mathrm{G}$, because of the loose dispersion of particles of each component in the BGSH mixture; this leads to an increased contact barrier for electron transport during electrochemical reaction, as shown in Figure $\mathrm{S} 3$. In $\mathrm{HC}-\mathrm{nSi} / \mathrm{G}$ composite, the nano $\mathrm{Si}$ is well coated with hard carbon and well attached to graphite bulk, which significantly reduce the contact area with the electrolyte and thus mitigates the parasitic reactions between electrode and electrolyte, resulting in suppressed formation of SEI layer on the electrode surface. The $\mathrm{R}_{\mathrm{ct}}$ value of $\mathrm{HC}-\mathrm{nSi} / \mathrm{G}$ is only $22.28 \Omega$ which is substantially lower than that of BGSH electrode (329 $\Omega$ ). The significantly lower kinetic barrier of $\mathrm{HC}-\mathrm{nSi} / \mathrm{G}$ composite is believed to originate from its unique architecture. The 
uniform hard carbon coating on nano $\mathrm{Si}$ and the superior contact with graphite both are beneficial for enhancing the electron transport during charge-transfer reaction. ${ }^{19}$

The electrochemical performance was evaluated by galvanostatic charge/discharge in the voltage range of $0.005 \sim 1.5 \mathrm{~V}\left(1 \mathrm{C}=600 \mathrm{~mA} \mathrm{~g}{ }^{-1}\right)$ and the specific capacity is calculated based on the active material (including $\mathrm{Si}$, graphite, and hard carbon). The electrode loading is $1.5 \sim 2.0 \mathrm{mg} \mathrm{cm}^{-2}$. Figure $3 \mathrm{a}$ shows the voltage profile of $\mathrm{HC}-\mathrm{nSi} / \mathrm{G}$ with different electrode combination (active materials, carbon black, and binder with the ratio of 7:1:2 and 8:1:1) in the 1st cycle at $0.05 \mathrm{C}$. A sample of $\mathrm{HC}-\mathrm{nSi} / \mathrm{G}$ with $10 \%$ of binder and $11.4 \%$ silicon (designated E1) exhibits a high reversible capacity of $659.1 \mathrm{mAh} \mathrm{g}^{-1}$ with a first cycle reversible capacity of $75.5 \%$. With the increase of Si content to $14.6 \%$ (the ratio of active materials, carbon black, and binder is still 8:1:1), the electrode (designated E2) delivers a high delithiation capacity of $764.1 \mathrm{mAh} \mathrm{g}^{-1}$ with the first cycle reversible capacity of $78.7 \%$. It is interesting that with $14.6 \%$ of silicon, further increasing the binder content to $20 \%$ (designated E3) significantly increase in the specific capacity of the electrode, delivering a reversible capacity of $878.6 \mathrm{mAh} \mathrm{g}^{-1}$ with an improved first cycle reversible capacity of $80.5 \%$. The result indicates that 1 ) carboxyl methyl cellulose (CMC) binder plays an important role as a dispersant to prepare a uniform electrode film, 2) CMC binder increases the integrity of electrode component due to the more dehydration reaction between carboxylic group in CMC and hydroxyl group in the $\mathrm{SiO}_{2}$ surface layer on $\mathrm{Si}$ or on hard carbon. ${ }^{20}$ The effects of binder and silicon contents on the cycling performances of the composite electrodes are presented in Figure 3b. For HCnSi/G with $10 \%$ binder and $11.4 \%$ of silicon, the electrode shows a relatively low reversible capacity of $638.6 \mathrm{mAh} \mathrm{g}^{-1}$ at $4^{\text {th }}$ cycle but very decent capacity retention of $92.1 \%$ over 150 cycles, due to the relatively low content of Si. For $\mathrm{HC}-\mathrm{nSi} / \mathrm{G}$ with $10 \%$ of binder and $14.6 \%$ of silicon (E2), the electrode exhibits a discharging capacity of $769.2 \mathrm{mAh} \mathrm{g}^{-1}$ in $4^{\text {th }}$ cycle and the retention is $75.2 \%$ over 150 cycles. On the other hand, HC-nSi/G with $20 \%$ of binder and $14.6 \%$ of silicon (E3) shows a capacity of 864.1 $\mathrm{mAh} \mathrm{g}^{-1}$ in $4^{\text {th }}$ cycle with $84.1 \%$ cycle retention until 150 cycles. In this regard, a balance between the contents of binder and the Si should be carefully considered during the development of Si/graphite 
composite electrodes, to control the volume expansion/contraction of the electrodes and maximize their electrochemical performances.
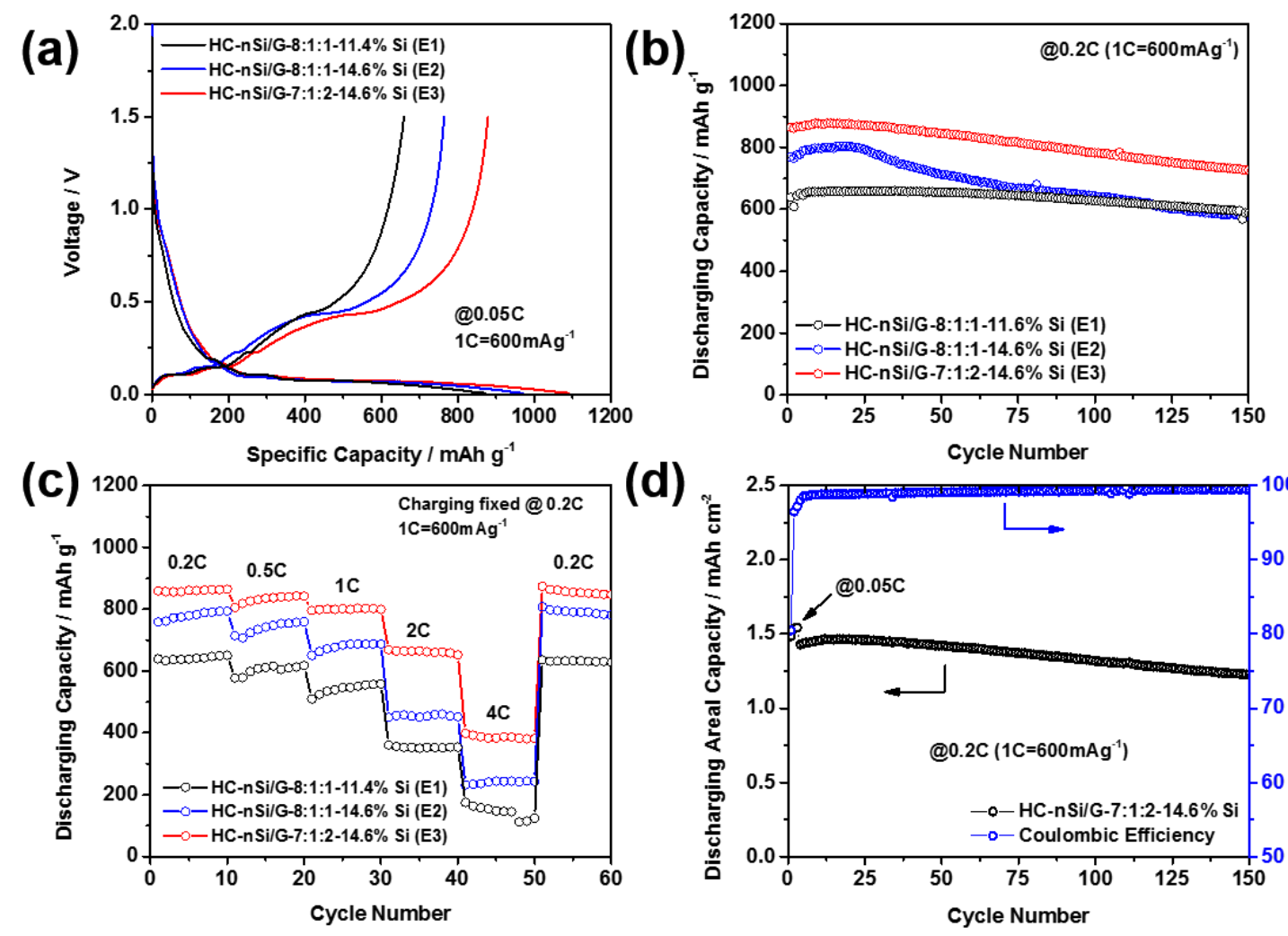

(d)

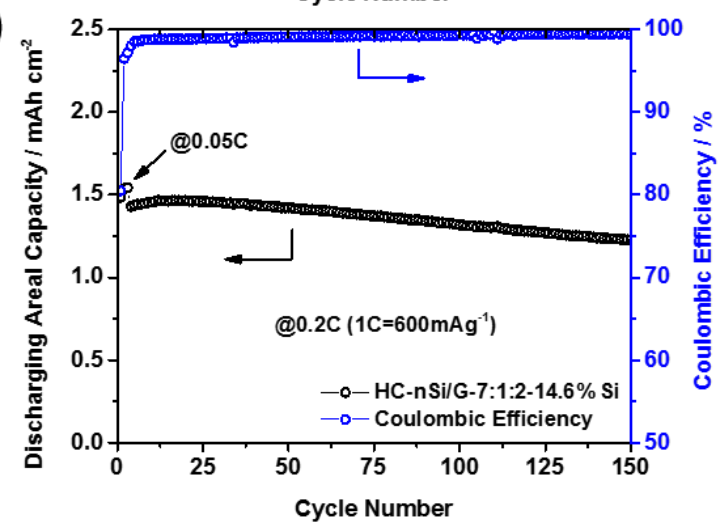

Figure 3. (a) Initial lithiation/delithiation voltage profiles at $0.05 \mathrm{C}$, (b) Specific capacity as a function of cycle number at $0.2 \mathrm{C}$, and (c) Rate capability of $\mathrm{HC}-\mathrm{nSi} / \mathrm{G}$ at various discharging C-rates (charging Crate fixed at $0.2 \mathrm{C}$ ) for $\mathrm{HC}-\mathrm{nSi} / \mathrm{G}$ with different electrode compositions (active material : carbon black : binder $=7: 1: 2$ or 8:1:1) and amounts of silicon (14.6\% and 11.4\%). (d) Plot of areal capacity retention of HC-nSi/G with electrode composition ratio (active material:carbon black:binder $=7: 1: 2$ ). Both electrodes are evaluated in the voltage range of $0.005 \sim 1.5 \mathrm{~V}\left(1 \mathrm{C}=600 \mathrm{~mA} \mathrm{~g}^{-1}\right)$.

With hard carbon coating and graphite to composite with nano-Si, the HC-nSi/G electrode shows much better cycling stability than nano-Si electrodes. Figure S4 shows the charge-discharge curves and cycling stability of the control nano-Si electrodes without hard carbon coating and graphite (nano-Si active material, carbon black, and binder with the ratio of $8: 1: 1)$. At similar Si loading in the electrode ( 2 to 3 
$\mathrm{mAh} \mathrm{g}^{-1}$ ), the specific capacity quickly fades to nearly $\sim 0 \mathrm{mAh} \mathrm{g}^{-1}$ within 10 cycles even though the initial capacity is $\sim 3700 \mathrm{mAh} \mathrm{g}^{-1}$.

Rate capabilities of the $\mathrm{HC}-\mathrm{nSi} / \mathrm{G}$ composite electrodes with different compositions were further evaluated and the result is illustrated in Figure 3c. Overall, the $\mathrm{HC}-\mathrm{nSi} / \mathrm{G}$ composite electrodes show very decent rate capability when discharging at $\mathrm{C}$ rates ranging from $0.2 \mathrm{C}$ to $4 \mathrm{C}$ under same charging $\mathrm{C}$ rate of 0.2C. The E3 electrode exhibits the highest discharging capacity compared to E1 and E2, delivering 860 $\mathrm{mAh} \mathrm{g}^{-1}, 806 \mathrm{mAh} \mathrm{g}^{-1}, 797 \mathrm{mAh} \mathrm{g}^{-1}, 669 \mathrm{mAh} \mathrm{g}^{-1}$, and $398 \mathrm{mAh} \mathrm{g}^{-1}$ at rates of $0.2,0.5,1,2$, and $4 \mathrm{C}$, respectively. After the rate test, a high discharge capacity of $874.5 \mathrm{mAh} \mathrm{g}^{-1}$ can be recovered for the E3 electrode when the discharge current density is returned to $0.2 \mathrm{C}$, further evidencing the good reversibility of the E3 electrode. The rate performances of $\mathrm{HC}-\mathrm{nSi} / \mathrm{G}$ composite electrodes are much better than the BGSH electrode (Figure S5), confirming the advantages of the preparation of integrated HC-nSi/G composite. Figure $3 \mathrm{~d}$ shows the areal capacity as a function of cycle number of E1 electrode. The electrode exhibits an areal capacity of ca. $1.5 \mathrm{mAh} \mathrm{cm}^{-2}$ during formation cycles at $0.05 \mathrm{C}$ and an areal capacity of $1.43 \mathrm{mAh} \mathrm{cm}^{-2}$ when the current density was increased to $0.2 \mathrm{C}$. A high areal capacity of 1.23 $\mathrm{mAh} \mathrm{cm}^{-2}$ is retained after 150 th cycles at $0.2 \mathrm{C}$ rate, corresponding to a high capacity retention of $86 \%$. Moreover, the Coulombic efficiency of the E1 electrode increases to $>99.0 \%$ during long-term cycling. In practical applications, a first cycle capacity loss of $<10 \%$ is required for the anode. In order to reduce the first cycle loss, pre-lithiation of Si based anode was performed with stabilized lithium metal powder (SLMP) before half-cell assembly. ${ }^{21,}{ }^{22}$ Figure 4 a illustrates the charge/discharge voltage profiles in the 1st formation cycle, showing that the open-circuit voltage (OCV) of the composite electrodes are influenced by the amount of SLMP used for pre-lithiation. For the E1 electrode without the addition of SLMP, the OCV value is $\sim 2.6 \mathrm{~V}$ while the E3 electrodes pre-lithiated with $7.5 \%$ and $8.3 \%$ of SLMP exhibit an OCV of $0.76 \mathrm{~V}$ and $0.37 \mathrm{~V}$, respectively. That is because the insertion of lithium induces the decrease of electrochemical potential of $\mathrm{HC}-\mathrm{nSi} / \mathrm{G}$ composite versus $\mathrm{Li} / \mathrm{Li}^{+}$. The $\mathrm{E} 1$ electrode without pre-lithiation exhibits a first cycle capacity retention of $80.4 \%$ while the electrodes pre-lithiated with $7.5 \%$ and $8.3 \%$ SLMP can increase the first cycle capacity retention to $85.8 \%$ and $93.1 \%$, respectively. 
The pre-lithiated E1 electrode shows similar cycling performance as compared to the electrode without pre-lithiation, as shown in Figure 4b. It is speculated that the slight reduction of discharge capacity for the pre-lithiated E1 electrode is originated from the unstable SEI formation in 1st formation cycle. ${ }^{23}$ It is noted that the electrolyte is reduced at the voltage range of $0.8 \sim 1 \mathrm{~V}$ during the 1 st discharge, resulting in SEI formation and this layer prevents further electrolyte degradation, which improves cycling performance in the subsequent cycles. ${ }^{24}$
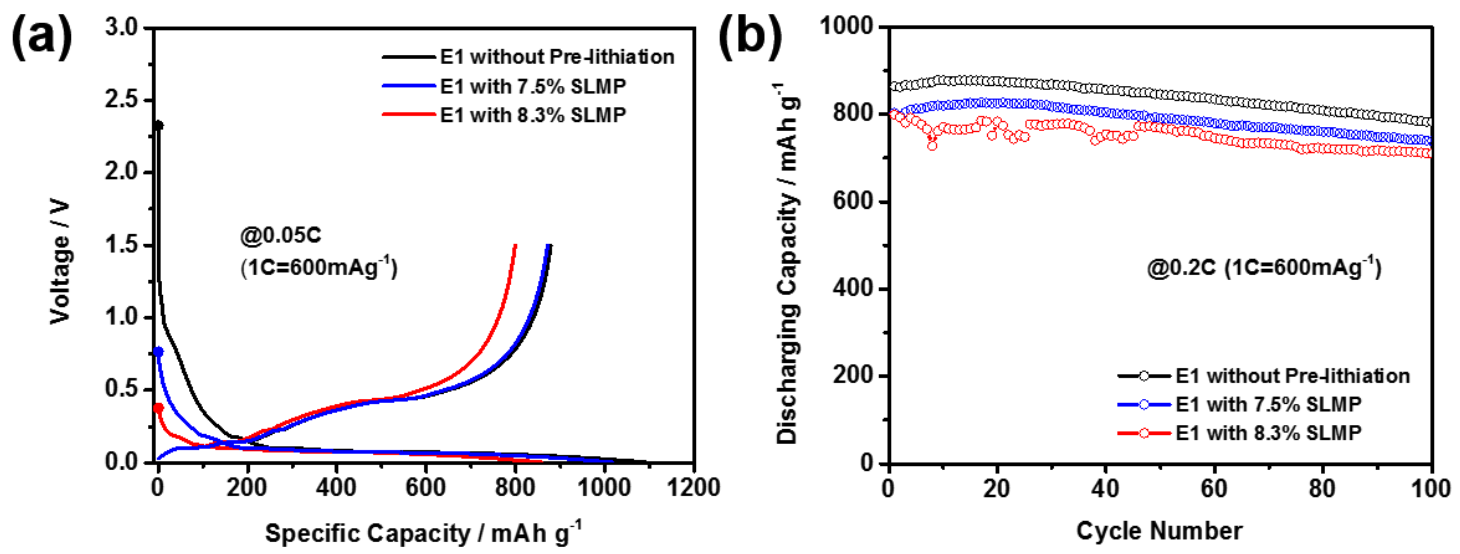

Figure 4. (a) Initial voltage profiles and (b) cycling performances of the E1 electrode before and after pre-lithiation step at $0.05 \mathrm{C}$ (full circle indicates the open-circuit voltage value; black: non-pre-lithiated electrode, blue: electrode with 7.5\% SLMP, red: electrode with 8.3\% SLMP).

In addition to minimizing the first cycle loss, practical applications also require to have high areal mass loading which is closely related to electrode thickness. In general, highly loaded electrodes have much poorer performance than thin electrodes, especially those with nanostructured materials. Thick electrode often leads to unstable SEI formation from internal stress generated during cycling for Si-based electrode. The electrochemical performances of HCnSi/G electrodes with different electrode loadings are shown in Figure 5 . In the $1^{\text {st }}$ formation cycle at $0.05 \mathrm{C}$, thick electrode $\left(5.9 \mathrm{mg} \mathrm{cm}^{-2}\right)$ exhibits slightly lower lithiation capacity of 930.4 
$\mathrm{mAh} \mathrm{g}^{-1}$ and an efficiency of $79.3 \%$ as compared to the relatively thin electrode $\left(2.4 \mathrm{mg} \mathrm{cm}^{-2}\right)$, which shows a capacity of $1071.6 \mathrm{mAh} \mathrm{g}^{-1}$ with $80.4 \%$ efficiency (Figure 5a). It is believed that this capacity reduction is due to mass transport limitations of lithium ions as well as increased impedance for electron transport in thick electrode. Also, Figure 5b shows the cycling performance of $\mathrm{HC}-\mathrm{nSi} / \mathrm{G}$ electrodes with different areal capacity loadings in a higher current density condition $\left(0.5 \mathrm{C}\right.$ corresponding to 0.72 and $1.77 \mathrm{~mA} \mathrm{~cm}^{-2}$ for the samples with a loading of 2.4 and $5.9 \mathrm{mg} \mathrm{cm}^{-2}$, respectively). The discharge capacity in $1^{\text {st }}$ cycle of the thick electrode is $2.55 \mathrm{mAh} \mathrm{cm}^{-2}$ during formation at $0.05 \mathrm{C}$ and comparable to commercial requirements. ${ }^{25}$ When the current density is increased to $0.5 \mathrm{C}$, the electrode is still capable of delivering a high areal capacity of more than $2.10 \mathrm{mAh} \mathrm{cm} \mathrm{cm}^{-2}$ and retains $>87.5 \%$ of its usable capacity after 70 cycles. The high specific capacity and areal capacity, as well as the good rate capability and cyclability of $\mathrm{HC}-\mathrm{nSi} / \mathrm{G}$ electrode validate it as a promising anode material for high performance LIBs. However, after 70 cycles, the capacity-fade of high loading samples at $0.5 \mathrm{C}$ (corresponding to charge/discharge at $1.77 \mathrm{~mA} \mathrm{~cm}^{-2}$ accelerated and retains only $1.40 \mathrm{mAh} \mathrm{cm}^{-2}$ at 100 cycles. We believe this is related to the corrosion of Li metal anode at high current densities $\left(>1 \mathrm{~mA} \mathrm{~cm}^{-2}\right)$ as reported in previous work. ${ }^{26}$ In contrast, the high loading samples cycled in an electrolyte with higher FEC content ( $20 \%$ instead of $10 \%$ ) exhibits much better cycling stability (with $81.8 \%$ of capacity retention after 100 cycles) as shown in Fig. 5b even at high current density of $1.77 \mathrm{~mA}$ $\mathrm{cm}^{-2}$. This result indicates that FEC can effectively suppress $\mathrm{Li}$ corrosion so a $\mathrm{Li} / \mathrm{Si}$ cell can sustain a long cycle life even at high current densities. Fig. 6 shows the cross section SEM image of the $\mathrm{HC}-\mathrm{nSi} / \mathrm{G}$ electrodes after 100 cycles. Comparing with the pristine $\mathrm{HC}-\mathrm{nSi} / \mathrm{G}$ particle shown in Fig. 1b, most of $\mathrm{HC}-\mathrm{nSi} / \mathrm{G}$ particles in the cycled electrodes still retained their 
original morphology. This is consistent with the good cycling stability of the composite electrode shown in Fig. 5.
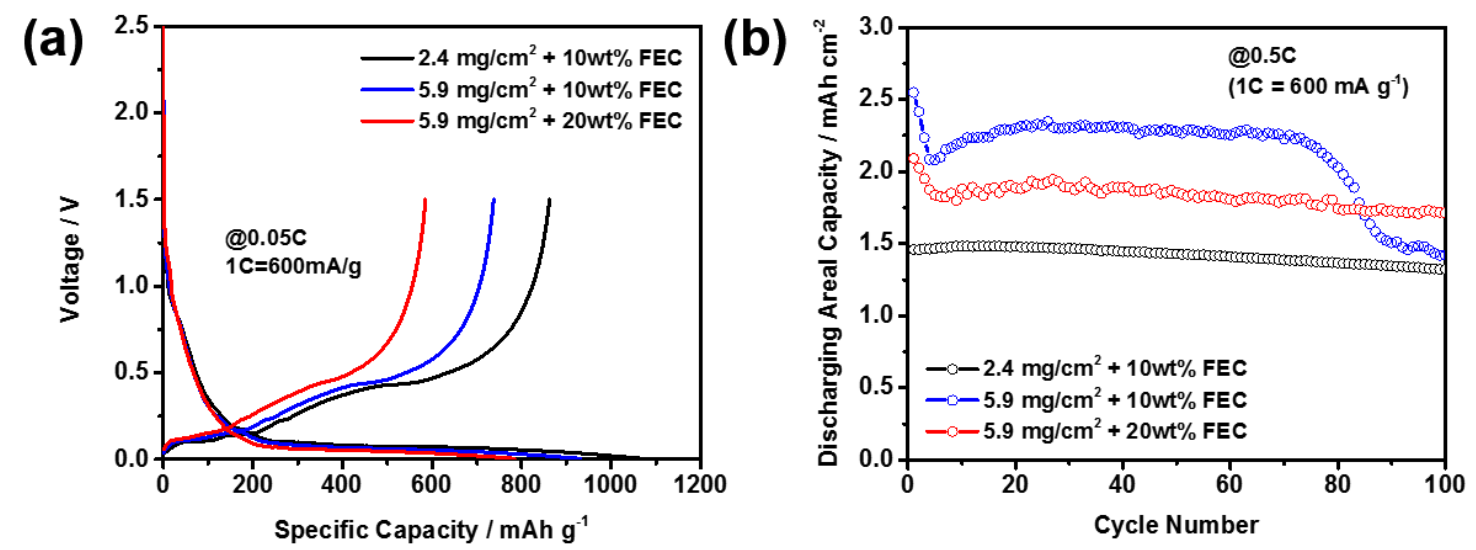

Figure 5. (a) First formation cycle voltage profiles and (b) cycling performances of the HC-nSi/G composite electrodes (E3) (14.6\% Si, active material: carbon black: binder = 7:1:2) with different loading levels $\left(2.4\right.$ and $\left.5.9 \mathrm{mg} \mathrm{cm}^{-2}\right)$.

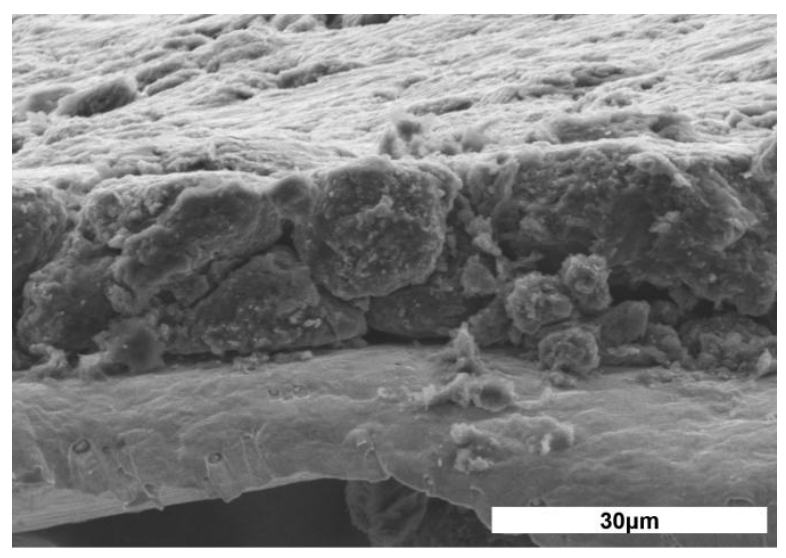

Figure 6. The cross section SEM image of the HC-nSi/G electrodes after 100 cycles.

\section{Conclusion}

In summary, we have successfully demonstrated a cost-effective and scalable approach to prepare a HC$\mathrm{nSi} / \mathrm{G}$ composite as a high performance anode material for LIBs. The HC-nSi/G composite shows much higher reversible capacity and rate capability as compared to its counterpart prepared by simply mixing the hard carbon, nano Si and graphite with exactly the same composition. With an optimized electrode 
composition, an $\mathrm{HC}-\mathrm{nSi} / \mathrm{G}$ electrode has demonstrated a reversible specific capacity of $879 \mathrm{mAh} \mathrm{g}^{-1}$ with an excellent cycling stability at an areal capacity loading $>2 \mathrm{mAh} \mathrm{cm}^{-2}$. The promising performances of HC-nSi/G composite are ascribed to its hierarchical structure, in which the hard carbon coating allows efficient electron transport and acts as a buffer layer for volume variation of silicon during electrochemical reactions. The fundamental findings of this work also shed light on the importance of binder content and the necessity of developing a more suitable binder to enable the long-term cycling performances of Si-based anode at a reasonably low cost.

\section{Acknowledgments}

This work was supported by the Assistant Secretary for Energy Efficiency and Renewable Energy, Office of Vehicle Technologies, Advanced Battery Materials Research (BMR) programs of the U.S. Department of Energy (DOE) under contract no. DE-AC02-05CH11231, subcontract no. 18769. The SEM/TEM observations were conducted in the William R. Wiley Environmental Molecular Sciences Laboratory (EMSL), a national scientific user facility sponsored by DOE's Office of Biological and Environmental Research and located at Pacific Northwest National Laboratory (PNNL). PNNL is operated by Battelle

for the DOE under Contract DE-AC05-76RLO1830. S. Jeong would like to thank Dr. Daiwon Choi and Dr. Estevez Luis for their useful discussions. 


\section{References}

[1]. D. Aurbach, O. Youngman, P. Dan, Electrochim. Acta 35 (1990), 639-655.

[2]. M. M. Thackeray, C. Wolverton, E. D. Isaacs, Energy \& Environ. Sci. 5 (2012), 7854-7863.

[3]. M. N. Obrovac, L. Christensen, Electrochem. Solid-State Lett. 7 (2004), A93-A96.

[4]. X. H. Liu, L. Zhong, S. Huang, S. X. Mao, T. Zhu, J. Y. Huang, ACS Nano 6 (2012), 1522-1531.

[5]. U. Kasavajjula, C. Wang, A. J. Appleby, J. Power Sources 163 (2007), 1003-1039.

[6]. C. K. Chan, H. Peng, G. Liu, K. Mcllwrath, X. F. Zhang, R. A. Huggins, Y. Cui, Nat. Nanotech. 3 (2008), 31-35.

[7]. M.-H. Park, M. G. Kim, J. Joo, K. Kim, J. Kim, S. Ahn, Y. Cui, J. Cho, Nano Lett. 9 (2009), 3844-3847.

[8]. H. Kim, M. Seo, M.-H. Park, J. Cho, Angew. Chem. Int. Ed. 49 (2010), 2146-2149.

[9]. N. Liu, H. Wu, M. T. McDowell, Y. Yao, C. Wang, Y. Cui, Nano Lett. 12 (2012), 3315-3321.

[10]. L.-F. Cui, Y. Yang, C.-M. Hsu, Y. Cui, Nano Lett. 9 (2009), 3370-3374.

[11]. M. Yoshio, T. Tsumura, N. Dimov, J. .Power Sources 146 (2005), 10-14.

[12]. D. Aurbach, O. Youngman, Y. Gofer, A. Meitav, Electrochim. Acta 35 (1990), 625-638.

[13]. D. He, F. Bai, L. Li, L. Shen, H. H. Kung, N. Bao, Electrochim. Acta 169 (2015), 409-415.

[14]. L. Roldán, I. Santos, S. Armenise, J. M. Fraile, E. García-Bordejé, Carbon 50 (2012), 1363-1372.

[15]. X. H. Liu, J. Y. Huang, Energy \& Environ. Sci. 4 (2011), 3844-3860.

[16]. X. Chen, X. Li, F. Ding, W. Xu, J. Xiao, Y. Cao, P. Meduri, J. Liu, G. L. Graff, J.-G. Zhang, Nano Lett. 12 (2012), 4124-4130.

[17]. M. D. Levi, D. Aurbach, J. Electroanalyt. Chem. 421 (1997), 79-88.

[18]. M. D. Levi, C. Wang, J. S. Gnanaraj, D. Aurbach, J. Power Sources 119-121 (2003), 538-542.

[19]. T. M. Pappenfus, W. A. Henderson, B. B. Owens, K. R. Mann, W. H. Smyrl, J. Electrochem. Soc. 151 (2004), A209-A215.

[20]. J. Li, R. B. Lewis, J. R. Dahn, Electrochem. Solid-State Lett. 10 (2007), A17. 
[21]. Z. Wang, Y. Fu, Z. Zhang, S. Yuan, K. Amine, V. Battaglia, G. Liu, J. Power Sources 260 (2014), 57-61.

[22]. N. Liu, L. Hu, M. T. McDowell, A. Jackson, Y. Cui, ACS Nano 5 (2011), 6487-6493.

[23]. P. Arora, R. E. White, M. Doyle, J. .Electrochem. Soc. 145 (1998), 3647-3667.

[24]. P. Verma, P. Maire, P. Novák, Electrochim. Acta 55 (2010), 6332-6341.

[25]. N. Nitta, G. Yushin, Particle \& Particle Systems Characterization 31 (2014), 317-336.

[26]. D. P. Lv, Y. Y. Shao, T. Lozano, W. D. Bennett, G. L. Graff, B. Polzin, J. G. Zhang, M. H.

Engelhard, N T. Saenz, W. A. Henderson, P. Bhattacharya, J. Liu, J. Xiao, Adv. Energy Mater. 5 (2015), 1400993.

[27]. V. Etacheri, O. Haik, Y. Goffer, G. A. Roberts, I. C. Stefan, R. Fasching, D. Aurbach, Langmuir 28 (2012), 965-76. 